\title{
Functional analysis of the Saccharomyces cerevisiae DUP240 multigene family reveals membrane-associated proteins that are not essential for cell viability
}

\author{
Rémy Poirey, ${ }^{1,2}$ Laurence Despons ${ }^{2}, V^{2}$ ronique Leh, ${ }^{2}$ \\ Maria-Jose Lafuente, ${ }^{1}+$ Serge Potier, ${ }^{2}$ Jean-Luc Souciet ${ }^{2}$ \\ and Jean-Claude Jauniaux ${ }^{1}$
}

\footnotetext{
1 Angewandte

Tumorvirologie, Abteilung F0100 and Virologie Appliquée à l'Oncologie (Unité INSERM 375), Deutsches

Krebsforschungszentrum, P. 1011949, D-69009 Heidelberg, Germany

2 Laboratoire de Génétique et Microbiologie, UPRES-A 7010 ULP/CNRS, Institut de Botanique, 28 rue Goethe, F-67083 Strasbourg cedex, France
}

\author{
Author for correspondence: Jean-Claude Jauniaux. Tel: +49 6221424971 . Fax: +49622142524971. \\ e-mail: j.jauniaux@dkfz.de
}

\begin{abstract}
The DUP240 gene family of Saccharomyces cerevisiae is composed of 10 members. They encode proteins of about 240 amino acids which contain two predicted transmembrane domains. Database searches identified only one homologue in the closely related species Saccharomyces bayanus, indicating that the DUP240 genes encode proteins specific to Saccharomyces sensu stricto. The short-flanking homology PCR gene-replacement strategy with a variety of selective markers for replacements, and classical genetic methods, were used to generate strains deleted for all 10 DUP240 genes. All of the knock-out strains were viable and had similar growth kinetics to the wild-type. Twohybrid screens, hSos1p fusions and GFP fusions were carried out; the results indicated that the Dup240 proteins are membrane associated, and that some of them are concentrated around the plasma membrane.
\end{abstract}

Keywords: gene disruption, membrane protein, gene tandem repeats, two-hybrid system, yeast

\section{INTRODUCTION}

Multigene families have been found in all sequenced organisms. In Arabidopsis thaliana gene duplication is as high as $65 \%$ (Arabidopsis Genome Initiative, 2000). These paralogous genes have similar sequences. There are numerous, more or less ancient, examples that reflect different situations: tRNA genes dispersed throughout the genome; rRNA genes gathered in clusters; dispersion and lower duplication levels for the genes encoding ribosomal proteins. The duplication phenomenon is observed for genes with known and unknown functions. Studying these multigenic families should provide useful information about the functions of the different copies and also about how they are involved in genome dynamics.

Saccharomyces cerevisiae S288C potentially encodes 5651 ORFs (Malpertuy et al., 2000). Of these, 914

\footnotetext{
†Present address: Centro de Biologia Molecular Severo Ochoa, Universidad Autonoma, Canto Blanco, 28049, Madrid, Spain.

Abbreviation: GFP, green fluorescent protein.
}

$(16 \cdot 2 \%)$ belong to two-gene families and $1544(27 \cdot 3 \%)$ belong to multigene families with between three and over 20 members (Blandin et al., 2000). In some cases, there are physiological reasons for the presence of multigene families. For example the cytoplasmic and mitochondrial methionyl-tRNA synthetases are encoded by two related but different nuclear genes, resulting in different localizations (Schneller et al., 1978). The genes encoding alcohol dehydrogenase (ADHI and $A D H I I)$ are very similar, but $A D H I$ catalyses the formation of ethanol from acetaldehyde whereas ADHII catalyses the formation of acetaldehyde from ethanol (Johnston \& Carlson, 1992). Another well-studied case is the CUP1 locus, which encodes a copper- or cadmium-chelating metallothionein expressed after induction with metals. The reference strain, S288C, contains only two copies of CUP1, but copper- or cadmium-resistant strains can contain up to 15 copies (Karin et al., 1984). The expression of most hexose transporters is tightly regulated by glucose concentration, starvation, osmotic pressure and the physiological state of the cells. In fact, to abolish glucose consumption and transport activity completely, all 18 members of the hexose transporter family, HXT1-17, GAL2 and three members of the 


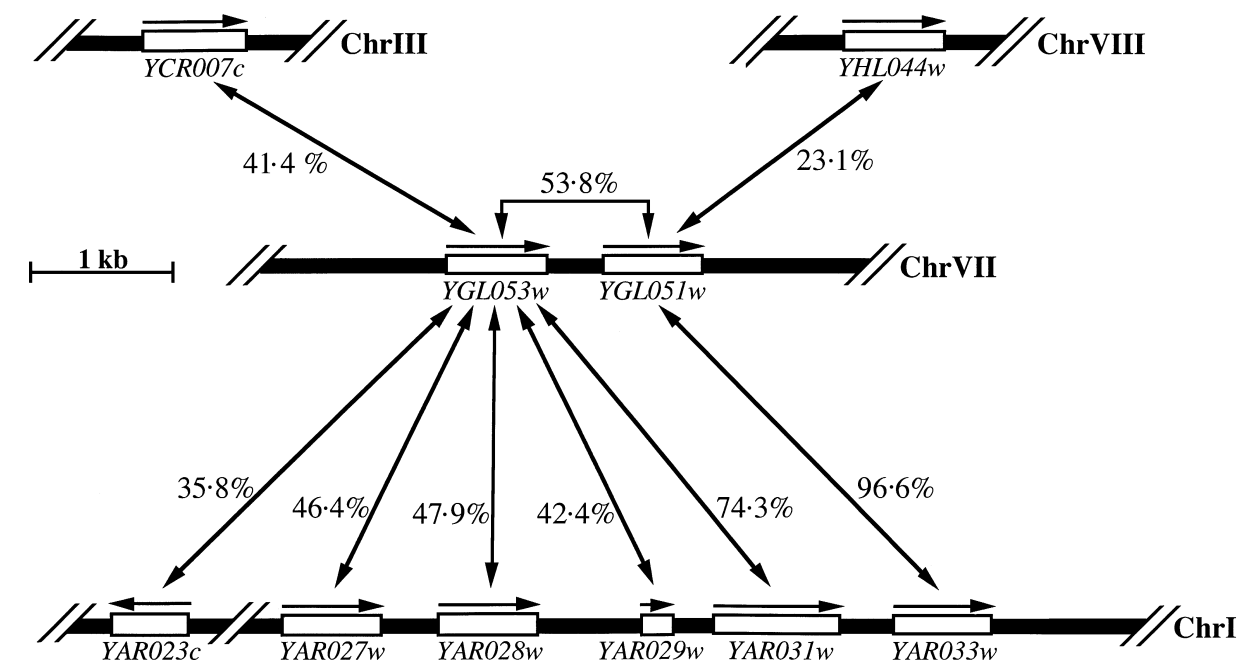

Fig. 1. Map of the genetic organization, chromosome localization and predicted amino acid sequence identities of the 10 DUP240 ORFs of S. cerevisiae. The ORFs are represented by rectangles, their orientation with respect to the centromeres by arrows. The percentages show the level of amino acid identities between the indicated ORF products.

maltose transporter family (AGT1, YDL247w and YJR160c) have to be deleted (Wieczorke et al., 1999).

In comparison with these established examples and with the exception of the PAU and OSBP families (Rachidi et al., 2000; Beh et al., 2001), the large gene families identified by sequencing programmes remain mostly unstudied. This is the case for the DUP240 gene family. This family is particularly interesting because of its unusually high copy number (10), the high level of nucleotide identity between some of its members and the specific chromosomal organization of the members (Fig. 1). The YAR027w, YAR028w, YAR029w, YAR031w and YAR033 $w$ ORFs are arranged as tandem repeats on chromosome I and the YGL051 $w$ and YGL053w ORFs are arranged as tandem repeats on chromosome VII. The nucleotide sequences of YAR033w and YAR031w are $98 \%$ identical to those of YGL051w and YGL053w (Feuermann et al., 1997). Most of the corresponding proteins are approximately 240 aa long. Moreover, these ORFs appear to be specific for the Saccharomyces sensu stricto group (Bon et al., 2000).

We carried out a functional analysis of these genes to get some insight into the role of the proteins which they encode. We replaced all 10 members of the DUP240 family and screened for associated phenotypes using the criteria defined by the EUROFAN network (Dujon, 1998; Oliver et al., 1998). Green fluorescent protein (GFP) fusion fluorescence was subsequently used to study the subcellular localization of the different ORF products. Activation of the RAS signalling pathway through hSos1p-Dup fusions and the classical GAL4based nuclear two-hybrid system were used to determine whether some of the Dup240 proteins were localized at the plasma membrane and to search for partners that interact with the products of the YGL051w and YGL053w genes. Our results indicated that the DUP240 gene family encodes membrane-associated proteins that are not essential for cell viability.

\section{METHODS}

Yeast strains and media. The Saccharomyces cerevisiae strains used in this study are listed in Table 1. Cells were grown on YPD $[1 \%$ yeast extract, $2 \%$ peptone, $2 \%$ glucose (dextrose) and $2 \%$ agar], YPG $(1 \%$ yeast extract, $2 \%$ peptone, $2 \%, v / v$, glycerol and $2 \%$ agar) and SD [6.7 g yeast nitrogen base $1^{-1}$, $2 \%$ glucose (dextrose) and $2 \%$ agar] supplemented with the amino acids and bases not required for the selection. The same media without agar were used for liquid cultures. Synthetic complete glucose medium (SC) was used for the two-hybrid selections (Sherman et al., 1986). Sporulation of diploids required growth on YPD overnight at $30{ }^{\circ} \mathrm{C}$ prior to transfer onto sporulation plates ( $1 \%$ potassium acetate and $2 \%$ agar) for $3-5$ days at $30^{\circ} \mathrm{C}$.

PCR-mediated gene replacements. The primers used for PCRmediated gene disruption consisted of 40-60 nt specific to sequences just upstream or downstream from the ORF to be deleted followed at the $3^{\prime}$ end of the primers by $18-20$ bases homologous to the upstream or downstream flanking region of a selectable marker gene located in a yeast integrating vector (Table 2). PCR conditions were: $94^{\circ} \mathrm{C}$ for $2 \mathrm{~min}$, $\left(94{ }^{\circ} \mathrm{C}\right.$ for $30 \mathrm{~s}, 54^{\circ} \mathrm{C}$ for $30 \mathrm{~s}, 72{ }^{\circ} \mathrm{C}$ for $\left.2 \mathrm{~min}\right) \times 30$ cycles, $72{ }^{\circ} \mathrm{C}$ for $10 \mathrm{~min}$. The specific PCR products were treated with phenol/chloroform prior to ethanol precipitation. Usually 1-5 $\mu \mathrm{g}$ amplified DNA was used to transform S. cerevisiae. High-efficiency transformations were performed by the method described by Gietz et al. (1995). Correct ORF replacements were checked by PCR analysis. Oligonucleotides were designed to bind outside the target loci (A1 and A4), within the target loci (A2 and A3) or within the marker genes (M2 and M3). In diploid yeast transformants with correctly integrated markers, one of the two copies of the target locus was replaced by the marker module. In PCR experiments with genomic yeast DNA and using either A1, A2 and M2 or M3, A3 and A4, the correct integration of the marker DNA was 
Table 1. S. cerevisiae strains

\begin{tabular}{|c|c|c|}
\hline Strain & Genotype & Source* \\
\hline SFY526 & 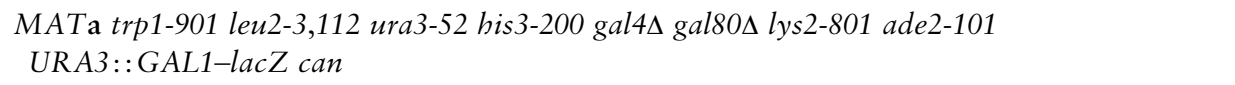 & Bartel et al. (1993b) \\
\hline PJ69-4a & 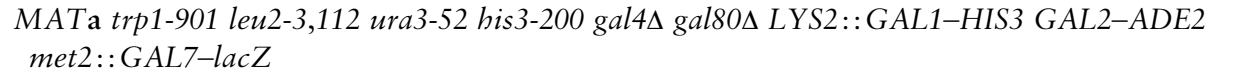 & James et al. (1996) \\
\hline PJ69-4 $\alpha$ & 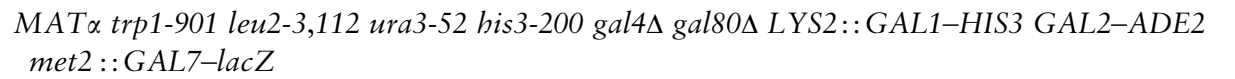 & P. James \\
\hline $\mathrm{CDC} 25 \mathrm{H}$ & MAT a ade2-801 cdc25-2 bis3-200 leu2-3,112 trp1-901 ura3-52 & Petitjean et al. (1990) \\
\hline \multicolumn{3}{|c|}{ (All subsequent strains are isogenic to S288C) } \\
\hline BY4709 & $M A T \alpha u r a 3 \Delta 0$ & ATCC 200872 \\
\hline FY1679 & 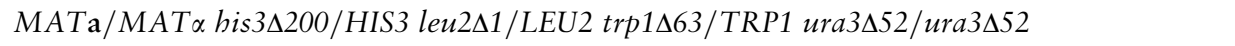 & ATCC 96604 \\
\hline FYBL1-17B & MATa his $3 \Delta 200 \operatorname{trp} 1 \Delta 63$ ura $3 \Delta 851$ & B. Dujon \\
\hline FYBL1-23D & $M A T \alpha$ his $3 \Delta 200 \operatorname{trp} 1 \Delta 63$ ura $3 \Delta 851$ & B. Dujon \\
\hline LD073 & 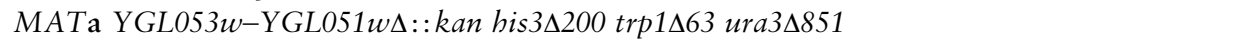 & This study \\
\hline LD076 & 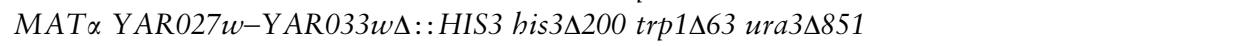 & This study \\
\hline LD078 & 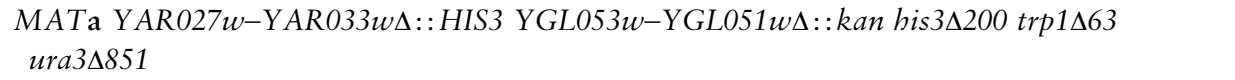 & This study \\
\hline BY4734 & $M A T \alpha$ his $3 \Delta 200$ leu $2 \Delta 0$ met $15 \Delta 0$ trp $1 \Delta 63$ ura $3 \Delta 0$ & ATCC 200896 \\
\hline LD084 & 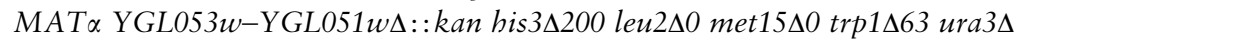 & This study \\
\hline LD099 & 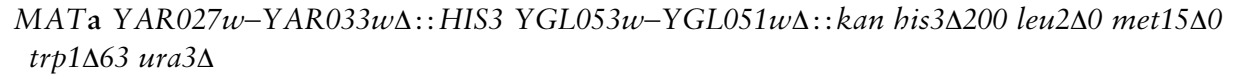 & This study \\
\hline LD100 & 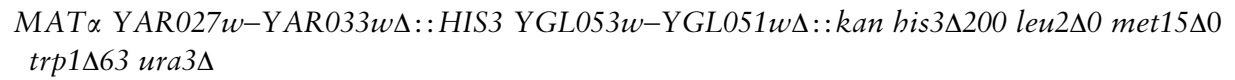 & This study \\
\hline LD102 & 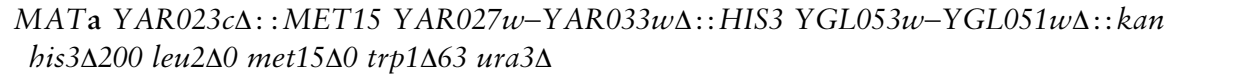 & This study \\
\hline LD103 & 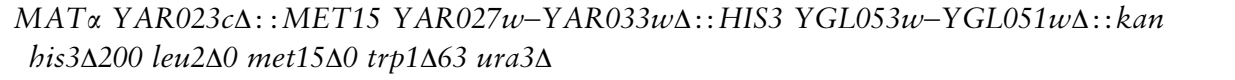 & This study \\
\hline LD107 & 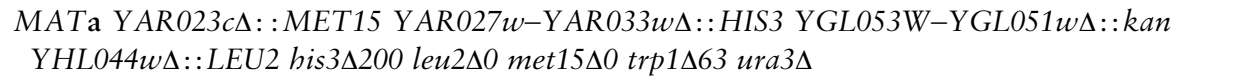 & This study \\
\hline LD108 & 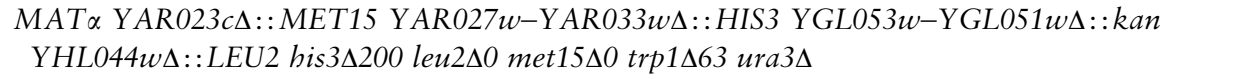 & This study \\
\hline LD115 & 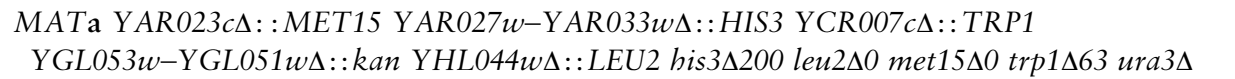 & This study \\
\hline LD114 & 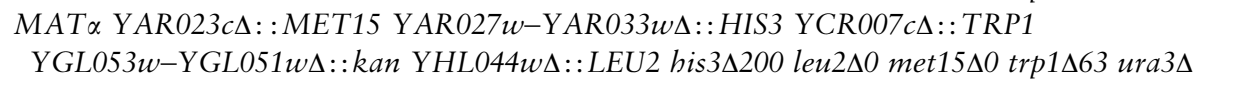 & This study \\
\hline
\end{tabular}

*ATCC, American Type Culture Collection, Manassas, VA, USA; P. James, University of Wisconsin, Madison, WI, USA; B. Dujon, Institut Pasteur, Paris, France.

confirmed by the appearance of two PCR products of the predicted length: one characteristic for the wild-type allele (A1-A2 or A3-A4 amplification product) and a second fragment characteristic for the mutated allele (A1-M2 or M3A4 amplification product). Incorrect transformants yielded only the amplification products of the wild-type allele.

DNA preparations and Escherichia coli transformation. Bacterial plasmid DNA preparations, bacterial transformations and DNA manipulations were carried out according to standard protocols (Sambrook et al., 1989). Yeast genomic DNA and plasmid DNA were purified according to the method described by Hoffman \& Winston (1987).

Cloning of a PCR product in a linearized plasmid by homologous recombination in yeast. Plasmids were linearized by two different endonucleases and dephosphorylated with calf intestine phosphatase (Boehringer). The sequences to be cloned were amplified by PCR (Saiki et al., 1985) from genomic DNA of yeast strain FY1679 with oligonucleotide primers having 20 additional nucleotides at the $5^{\prime}$ ends. These ends were homologous to the ends of the linearized plasmid and used for cloning by homologous recombination in this plasmid (Muhlrad et al., 1992). The PCR conditions were: $94^{\circ} \mathrm{C}$ for $1.5 \mathrm{~min},\left(94^{\circ} \mathrm{C}\right.$ for $30 \mathrm{~s}, 48^{\circ} \mathrm{C}$ for $2 \mathrm{~min}, 70^{\circ} \mathrm{C}$ for $2.5 \mathrm{~min}) \times 10$ cycles, $\left(94^{\circ} \mathrm{C}\right.$ for $30 \mathrm{~s}, 60^{\circ} \mathrm{C}$ for $2 \mathrm{~min}, 70^{\circ} \mathrm{C}$ for $2.5 \mathrm{~min}) \times 35$ cycles, $70^{\circ} \mathrm{C}$ for $10 \mathrm{~min}$. The PCR product and the linearized plasmid were treated with phenol/chloroform prior to ethanol precipitation. High-efficiency transformations were performed according to the method described by Gietz et al. (1995). For cloning in pGBT9 (Bartel et al., 1993a), pSOS (Stratagene) and pGRU1 (see below), the vector was linearized by EcoRI and SalI, NcoI and MluI, and EcoRI and SalI, respectively. The PCR product and the corresponding linearized plasmid were introduced into the yeast cells simultaneously. The oligonucleotide sequences are given in Table 2. We ensured that there were no errors in the junctions between the plasmid and the inserts for pGBT9-YGL051w and pGBT9YGL053w by sequencing. 
Table 2. Oligonucleotides used as primers to generate PCR products

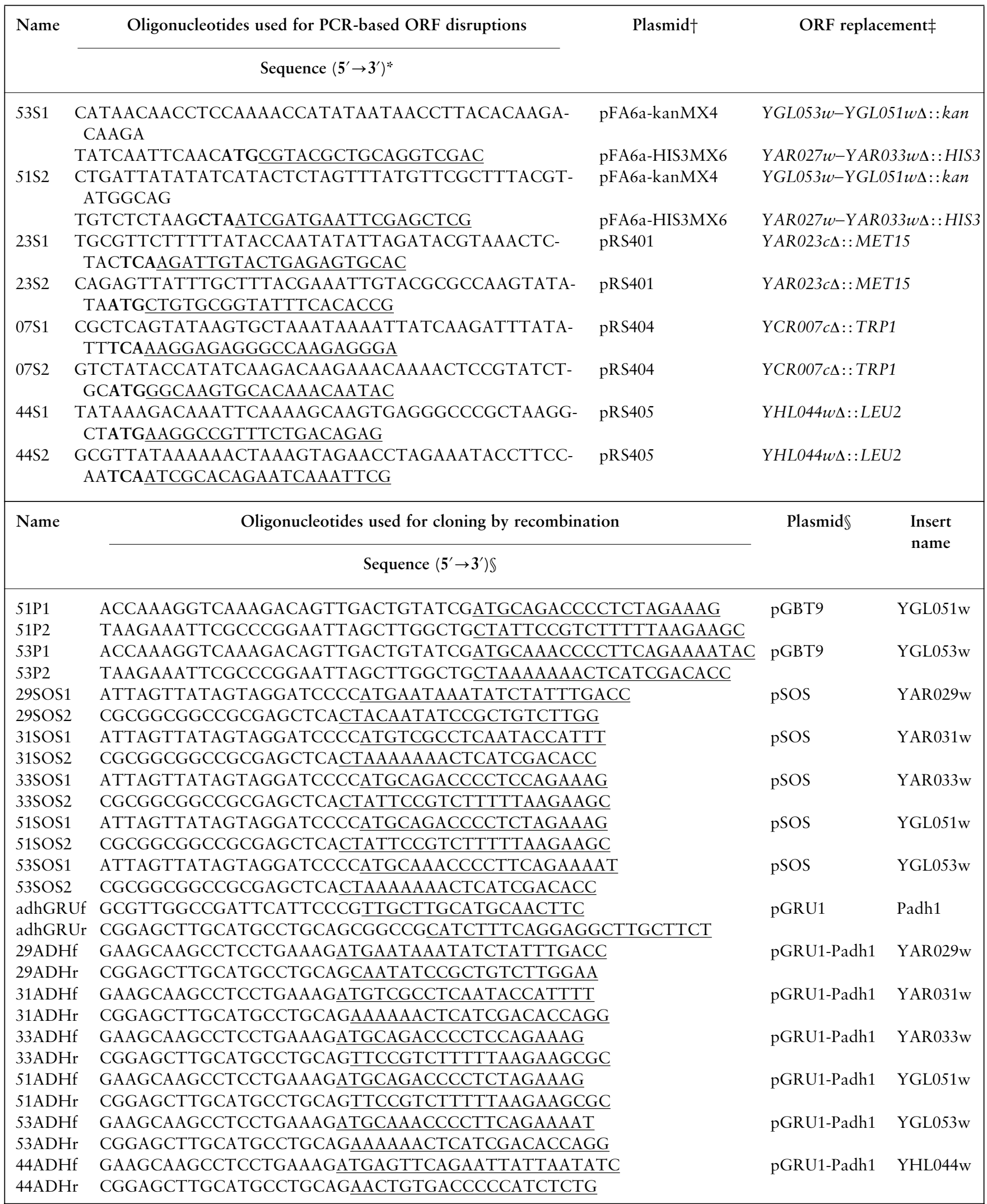

* The nucleotides at the $5^{\prime}$ end are homologous to the genomic DNA region just upstream or downstream from the gene to be replaced. The initiator or stop codon is shown in bold. The underlined nucleotides are homologous to the plasmid sequence upstream or downstream from the selectable marker gene. 
Determination of Dup240-GFP localization in vivo. The PCRamplified DUP240 ORFs were cloned in-frame at the Cterminal end of the green fluorescent protein-S65T (GFPS65T) gene of pGRU1 (Michel Aigle, IBGC, Bordeaux, France) and of pGRU1-Padh1. Transformed yeast cells were selected in SD medium without uracil because URA3 was used as the marker gene for selection of pGRU1. Dup240-GFP and control GFP were excited with a $488 \mathrm{~nm}$ laser and viewed under a Leica confocal microscope equipped with a $\times 63$ objective.

Activation of the RAS signalling pathway through hSos1pDup240 fusion. We modified the cytoplasmic two-hybrid system (Aronheim et al., 1997) marketed by Stratagene (CytoTrap) so that it would test for the presence of a hybrid protein at the plasma membrane. This system uses the $S$. cerevisiae mutant $\mathrm{CDC} 25 \mathrm{H}$, containing a thermosensitive mutation of the CDC25 gene product (Petitjean et al., 1990). This gene is homologous to the human hSOS1 gene (Chardin et al., 1993) and encodes a GDP/GTP exchange factor. By stimulating the exchange of GDP associated with the Ras1 and Ras2 proteins for GTP, Cdc25p stimulates the signalling pathway involving these proteins. hSos1p is cytoplasmic in the system. The $c d c 25 \mathrm{H}$ mutation prevents cell growth at $37^{\circ} \mathrm{C}$ while growth is normal at $25^{\circ} \mathrm{C}$. Cell growth can be restored by targeting hSos1p to the plasma membrane (Aronheim et al., 1994). To test whether Dup240 proteins can target hSos1p to the plasma membrane we constructed hSos1p-Dup240 fusion proteins by introducing PCR-amplified DUP240 ORFs into the pSOS vector (CytoTrap) in-frame at the $5^{\prime}$ end of the bSOS1 gene. We then tested the ability of the resulting constructions to restore the growth of the $\mathrm{CDC} 25 \mathrm{H}$ yeast strain (CytoTrap) at $37^{\circ} \mathrm{C}$. Drops of liquid control and transformed yeast cultures were deposited onto YPD plates and incubated for $2-3$ days at $37^{\circ} \mathrm{C}$ to evaluate growth.

Two-hybrid screen strategy. Two-hybrid screens were carried out using a system based on that described by Fields \& Song (1989). We used the Gal4pAD-yeast genomic library (mechanically sheared genomic DNA fragments with a mean size of $800 \mathrm{bp}$ inserted into the pACTII vector which bears the marker gene LEU2; A. Ramne \& P. Sunnerhagen, http:// www.mips.biochem.mpg.de/proj/eurofan/eurofan_1/b5/ index.html). This library was introduced (Georgakopoulos et al., 2001) into the haploid yeast PJ69-4a (Table 1). This strain contains three markers (HIS3, ADE2 and lacZ) controlled by three different GAL promoters (GAL1, GAL2 and GAL7, respectively), which can each be activated in the two-hybrid system (James et al., 1996). This library was composed of $2 \cdot 1 \times 10^{7}$ independent transformed yeast cells. It was amplified in liquid culture and aliquot vials containing $6.5 \times 10^{8}$ yeast cells were stored at $-80^{\circ} \mathrm{C}$. A mating strategy inspired by Bendixen et al. (1994) and modified by FromontRacine et al. (1997) was used to obtain a wide range of diploids containing both bait and target plasmids. High mating efficiency enabled us to test over $5 \times 10^{7}$ interactions per experiment. The haploid yeast PJ69-4 $\alpha$ (Table 1) was transformed with the bait cloned by homologous recombination and fused with the Gal4pBD (Gal4p-DNA binding domain) of the pGBT9 vector bearing the marker gene TRP1. For each screen, one vial containing $6.5 \times 10^{8}$ transformed PJ69-4a was mixed with $10^{9} \mathrm{PJ} 69-4 \alpha$ cells. Cells were concentrated onto filters and incubated on rich medium for $4.5 \mathrm{~h}$ at $30^{\circ} \mathrm{C}$ prior to collection. The cells were diluted and spread onto SC-Leu, SC - Trp and SC-Leu-Trp plates to count the number of parental cells and the number of diploids. The rest of the cell suspension was spread onto $24 \mathrm{SC}-\mathrm{Leu}-\mathrm{Trp}-$ His plates $(24 \mathrm{~cm} \times 24 \mathrm{~cm})$ containing $2 \mathrm{mM} 3$-aminotriazole. The plates were incubated at $30^{\circ} \mathrm{C}$ for 4 days. His-positive clones were subjected to a second selection on SC-Leu-Trp-adenine plates. Plasmids were rescued in E. coli HB101. Insert junctions with Gal4pAD were sequenced and precisely identified in the yeast genome using the MIPS (Munich Information Centre for protein sequences; http://mips.gsf.de) Yeast Genome Database (MYGD) or the Saccharomyces Genome Database from Stanford University (http://genome-www. stanford.edu/Saccharomyces).

$\beta$-Galactosidase filter assays to test the two-hybrid interactions in another genetic background. Yeast strain SFY526 was transformed by the LiAc method (Gietz et al., 1995) simultaneously with two plasmids which gave a two-hybrid interaction in PJ69-4 and spread onto SD - Leu - Trp agar in $150 \mathrm{~mm}$ diameter Petri plates. After 2 days at $30^{\circ} \mathrm{C}$ these plates were replicated onto $125 \mathrm{~mm}$ diameter filters, which were incubated on YPD medium plates for 1 day at $30^{\circ} \mathrm{C}$. The filters were frozen quickly in liquid nitrogen and put onto plates containing, in a total of $3.5 \mathrm{ml}: 58.5 \mu \mathrm{l} 2 \%$ $\mathrm{X}$-Gal in dimethylformamide, $9 \cdot 5 \mu \mathrm{l} \beta$-mercaptoethanol, $16 \cdot 1 \mathrm{~g}$ $\mathrm{Na}_{2} \mathrm{HPO}_{4} \cdot 7 \mathrm{H}_{2} \mathrm{O} \mathrm{l}^{-1}, 5 \cdot 5 \mathrm{~g} \mathrm{NaH}_{2} \mathrm{PO}_{4} \cdot \mathrm{H}_{2} \mathrm{O} \mathrm{l} l^{-1}, 0 \cdot 75 \mathrm{~g} \mathrm{KCl} \mathrm{l}^{-1}$ and $0 \cdot 246 \mathrm{~g} \mathrm{MgSO}_{4} \cdot 7 \mathrm{H}_{2} \mathrm{O} \mathrm{l}^{-1}$ at $\mathrm{pH} 7 \cdot 0$. The time required for yeasts to stain blue was measured at room temperature $\left(22^{\circ} \mathrm{C}\right)$.

\section{RESULTS}

\section{In silico analysis}

The 10 DUP240 ORFs constitute a large multigene family in the $S$. cerevisiae S288C strain. The relationships between the 10 encoded proteins are depicted in Fig. 2. The alignment of the protein sequences (Fig. 3) revealed five well-conserved domains: C1 (amino acids 1-44), C2 (amino acids 109-150), C3 (amino acids 206-224), H1 (amino acids 51-67) and H2 (amino acids 78-94). $\mathrm{H} 1$ and $\mathrm{H} 2$ are hydrophobic domains and because of their length they are predicted to be transmembrane domains (Klein et al., 1985). The ORF products Yar033p and Ygl051p have a very high level of identity $(96.6 \%)$, with only eight amino acid differences in a total of 234. Furthermore, six of these differences were within the 17 residues of the second predicted transmembrane domain (Fig. 3), but they did not affect the hydrophobicity of the domain. A genetic conversion

†The pFA6a series are reporter/marker plasmids (pFA, plasmids for Functional Analysis; Wach et al., 1994). Information on the sequences and availability of the pRS400 series of vectors is given in Brachmann et al. (1998).

‡ The ORF replacement cassette amplified with both 53S1 and 51S2 oligonucleotides allowed the replacement of either the region of chromosome VII between the YGL053w ORF and the YGL051w ORF or the region of chromosome I between the YAR027 $w$ ORF and the YAR033w ORF.

$\mathbb{S}$ The sequence corresponding to the insert is underlined; the rest of the sequence is homologous to the plasmid and was used for homologous recombination in yeast. 


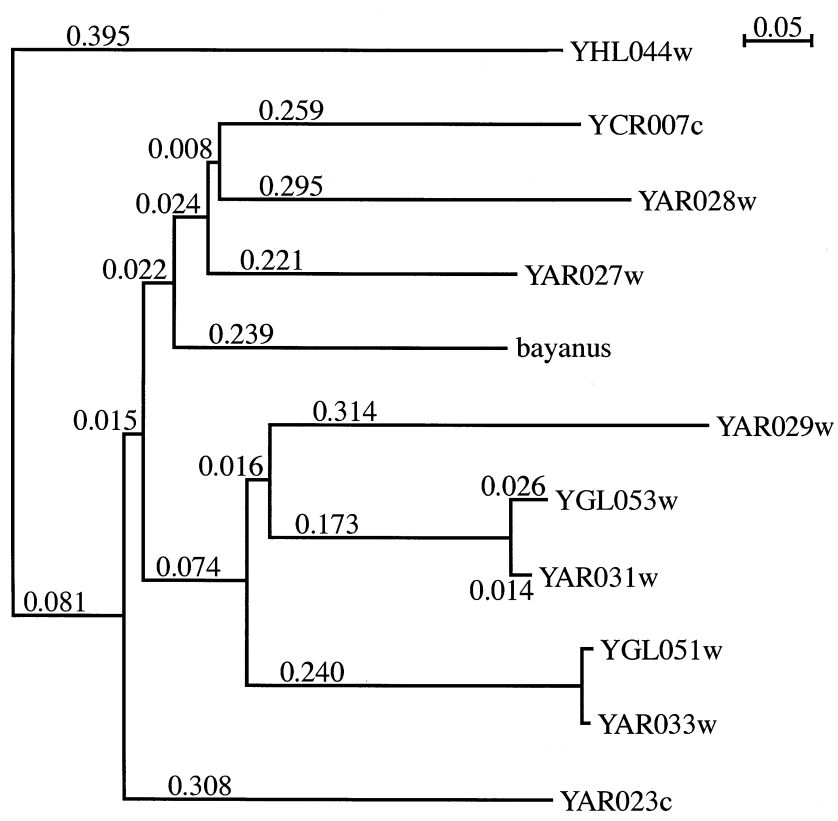

Fig. 2. Relationships between the amino acid sequences of the DUP240 ORF products from S. cerevisiae and the DUP240 orthologue from $S$. bayanus. The amino acid sequences were aligned by use of the CLUSTAL $x$ (1.8) program using the PAM protein matrix 40 . The tree was generated by the neighbourjoining method using the CLUSTAL w program. The Yar031p sequence was deleted of $62 \mathrm{~N}$-terminal residues.

event encompassing the corresponding nucleotide area, as observed for the FCY2 cluster (Wagner et al., 2001), could explain this local accumulation of point mutations, although we were unable to identify which sequence might have acted as the donor. Most of the ORF DUP240 products exhibit greater than $25 \%$ amino acid identity, suggesting that they share common architectural features (Sander \& Schneider, 1991). Until recently this protein family had only been detected in $S$. cerevisiae. However, an orthologue has now been identified in Saccharomyces bayanus var. uvarum (Bon et al., 2000) (Fig. 2). As the genome of S. bayanus was analysed by a random sequencing strategy with a genome coverage of $0 \cdot 3 \times$, it is not possible to speculate whether this ORF also belongs to a multigenic family in this species.

\section{The complete deletion of the 10 DUP240 ORFs does not result in an altered phenotype}

To determine the role of the DUP240 multigene family, all ORFs of this family were replaced by different marker genes and the phenotype of the corresponding strains was systematically analysed. The strategy employed to create a strain with a complete set of deletion alleles of DUP240 ORFs is summarized in Fig. 4. We used the PCR-mediated gene replacement method to replace the two tandemly repeated DUP240 ORFs of chromosome VII (YGL053w and YGL051w) with the kanMX4 gene. The five tandemly repeated DUP240
ORFs of chromosome I (YAR027w to YAR033w) were replaced with the HIS3 allele, and YAR023c, YHL044w and YCR007c were replaced by MET15, LEU2 and TRP1 markers, respectively. These different replacements were made in a diploid context. The LD114 and LD115 strains obtained by sporulation corresponded to haploid strains of opposite mating type and contained none of the DUP240 ORFs (Table 1, Fig. 4). Both strains were viable, showing that the 10 DUP240 ORFs are not essential for cell viability. These two strains grew similarly to the wild-type control strains with the same genetic background in all of the conditions tested (Fig. 5). Mating was carried out between MAT $\alpha$ LD114 and MATa LD115 strains to obtain homozygous deletants. The sporulation efficiency of the resulting diploids was similar to that of the wild-type and spores were able to produce colonies after germination. Thus, none of the DUP240 gene deletions resulted in an altered phenotype in any of the conditions tested (fermentable or respiratory carbon sources, growth temperature, mating, sporulation). In addition, because YGL052w is localized between YGL051w and YGL053w, the three ORFs were replaced simultaneously, allowing the conclusion that in the conditions tested the replacement of YGL052w does not alter the phenotype. No other hemiascomycetous yeasts contain a sequence corresponding to YGL052w (Souciet et al., 2000), and YGL052w overlaps with YGL051w; thus this ORF (Malpertuy et al., 2000) should no longer be considered as a coding sequence. The same is true for ORF YAR030c.

As the strain deleted for the 10 DUP240 ORFs did not have an altered phenotype in the tested conditions, we examined the subcellular localization of the 10 proteins to get further insight into their functions.

\section{Subcellular localization of different Dup240-GFP fusion proteins}

The ORFs YGL051w and YGL053w under the control of their own promoters were each individually cloned in-frame with the gene encoding GFP-S65T. The fluorescent signal yielded by the subsequent constructions on the multicopy plasmids (pGRU1-P-YGL051w and pGRU1-P-YGL053w, respectively) were hardly detectable. This result could be related to a low expression level as previously reported by Northern blot (Barton et al., 1997) and DNA array data (Jelinsky \& Samson, 1999). To enhance transcription, the yeast ADH1 promoter was introduced into pGRU1, such that the GFP-S65T gene was under the control of this strong promoter; the derivative plasmid was named pGRU1Padh1. The ORFs YGL051w, YGL053w, YAR029w, YAR033w, YAR031w and YHL044w were cloned inframe at the $5^{\prime}$ end of GFP-S65T ORF into this pGRU1Padh1, and each one was individually introduced into the reference strain FY1679.

The control experiment with the vector without the insert revealed the expected homogeneous distribution of GFP within the cytoplasm (Fig. 6). Ygl051p-, Ygl053p-, Yar033p-, Yar031p- and Yhl044p-GFP fu- 

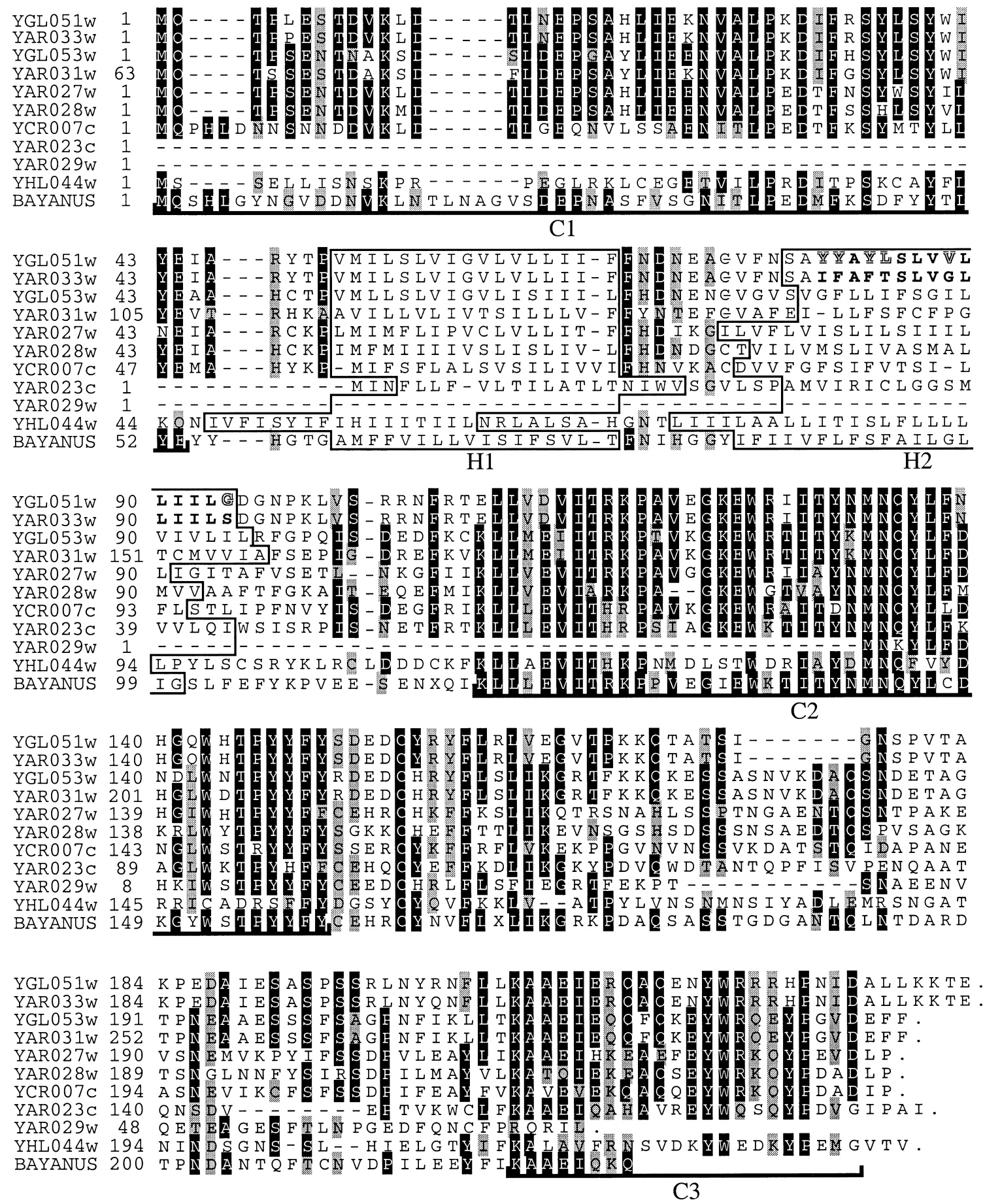

Fig. 3. Similarity between the highly conserved proteins encoded by the DUP240 family. The amino acid sequences were aligned by use of the CLUSTAL X (1.8) program and visually optimized. White on black, amino acid identity; shading, amino acid similarity; boxes, sites of the two predicted transmembrane domains; bold, 15 residues of Yar033p and Ygl051p where 6 (outlined) out of 8 amino acid differences between these two sequences are concentrated. YAR031w encodes an additional 62 aa at the N-terminal extremity compared to the other DUP240 family genes, YAR023c encodes about 50 aa less at the N-terminal end, and YARO29w encodes about 130 aa less at the N-terminal end and about 20 aa less at the Cterminal end, than the other members of the family. The DUP240 orthologue from S. bayanus is shorter because only a part of the sequence was available from the database (http://cbi.labri.u-bordeaux.fr/Genolevures/Genolevures.php3).

sion proteins were localized at the plasma membrane. The Yar031p- and Yhl044p-GFP fusion proteins appeared to concentrate as specific spots corresponding to a higher focal concentration at the plasma membrane. In addition Ygl051p-, Ygl053p- and Yar033p-GFP fusion proteins surrounded the nucleus, a situation typical of 


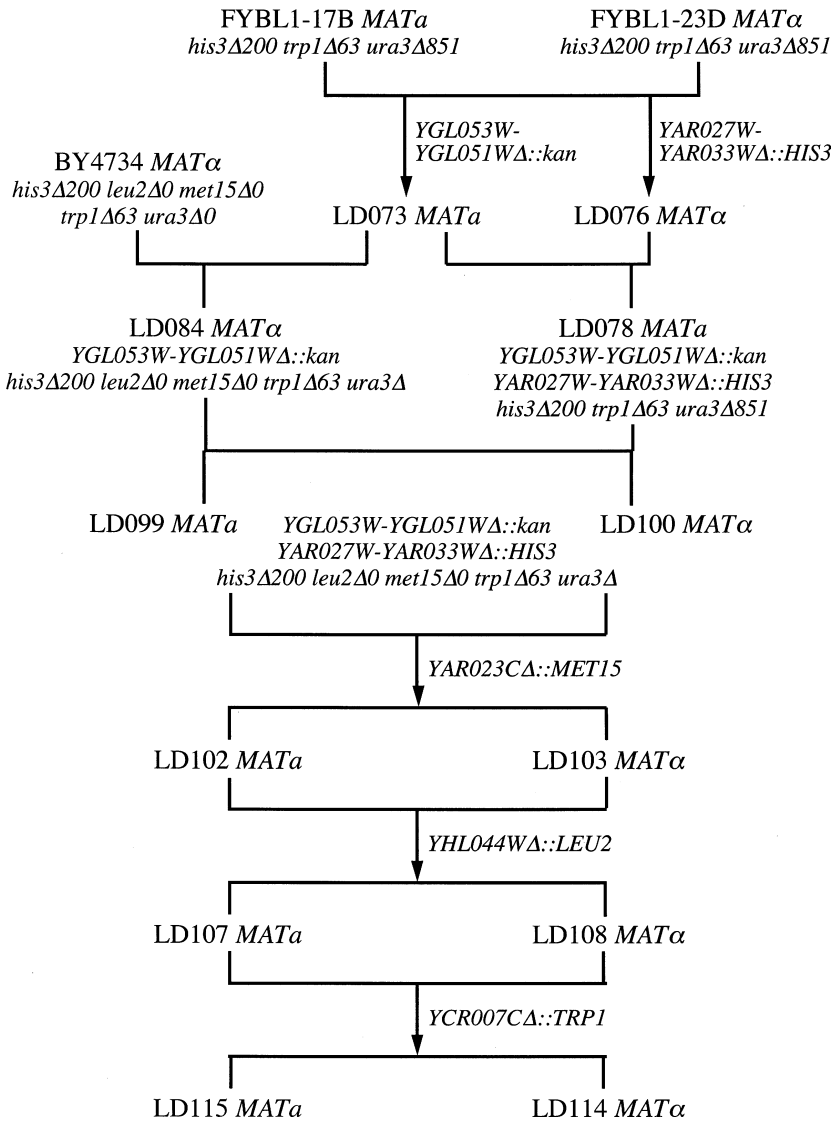

Fig. 4. Strategy used to construct the strains deleted for the 10 DUP240 ORFs. Lines with arrows indicate that the identified allele was introduced by PCR-mediated gene disruption. Lines connecting two strains define a mating between the two strains and lines without arrows indicate that a spore resulted from the mating. In some instances the genotypes of the spores are indicated. Strains LD114 and LD115 are deleted for all 10 DUP240 ORFs.

an endoplasmic reticulum localization. Moreover, Ygl053p- and Yar033p-GFP fusion proteins appeared to accumulate into additional membranes that could correspond to the Golgi apparatus. Conversely, the Yar029p-GFP fusion protein showed a similar distribution to GFP alone, but with additional spots corresponding to a higher focal concentration not linked to the plasma membrane. This could be because Yar029p is the shortest member of the Dup240 family and the only one that lacks the predicted transmembrane domain. The localization of the Dup240 protein at the plasma membrane was further addressed by studying the hSos1p-Dup240 fusion RAS signalling pathway activation system.

\section{A new strategy to test the localization of Ygl051p, Ygl053p and Yar033p at the plasma membrane level: hSos1p-Dup240 fusion}

We modified the cytoplasmic two-hybrid system developed by Aronheim et al. (1994) so that it could be used to detect proteins localized at the plasma mem-

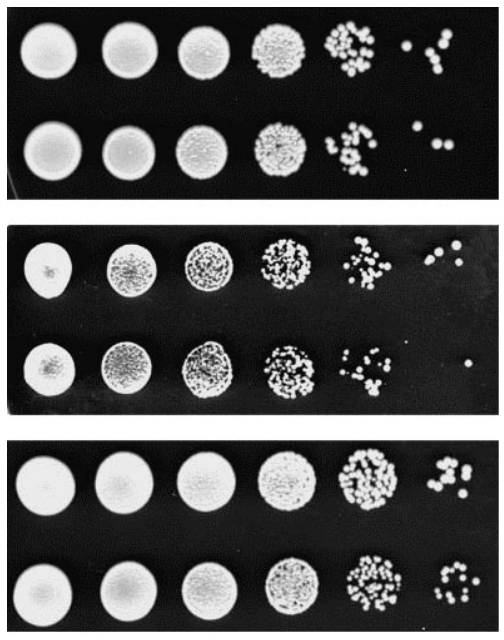

Fig. 5. The 10 DUP240 ORFs are not essential for cell viability. The LD114 mutant strain (lower rows of each tenfold dilution series of an overnight cell suspension) grew similarly to the BY4709 control strain (upper rows) on complete glucose medium (top panel), complete glycerol medium (middle panel) and minimal medium (bottom panel) after $2-5$ days at $30^{\circ} \mathrm{C}$. The same results were obtained at $15^{\circ} \mathrm{C}$ and $37^{\circ} \mathrm{C}$ (data not shown).

brane. This system is based on the activation of the Ras signalling pathway. The growth of the $c d c 25 H$ mutant (strain $\mathrm{CDC} 25 \mathrm{H}$ ) at the restrictive temperature requires the targeting of the tested hSos1p-Dup240 fusion protein to the plasma membrane. The YAR029w, YAR031w, YAR033w, YGL051 $w$ and YGL053w ORFs were cloned in-frame with the $h S O S 1$ gene, resulting in pSOSYAR029w, pSOS-YAR031w, pSOS-YAR033w, pSOSYGL051w and pSOS-YGL053w, respectively. These constructs were introduced into the yeast strain $\mathrm{CDC} 25 \mathrm{H}$. The constructions containing the YAR033w, YGL051 $w$ and YGL053w ORFs were able to restore the growth of the yeast cells. The correlation between the loss of the plasmid and the inability to grow at the restrictive temperature was verified. Growth was thus truly due to the presence of the coding sequences of one or other of these three ORFs, indicating that the corresponding fusion proteins were targeted to the plasma membrane.

This result can be explained by at least two mechanisms. Firstly, these bait proteins could interact physically with endogenous membrane protein targets, allowing the colocalization of the hSos1p protein at the plasma membrane. hSos1p could then fulfil its deoxyriboguanosine exchange function. Alternatively, the bait proteins Yar033p, Ygl051p and Ygl053p may themselves be membrane proteins. This would localize the fused $\mathrm{hSos} 1 \mathrm{p}$ protein at the plasma membrane, allowing it to fulfil its role as an enzyme.

The fusion proteins hSos $1 \mathrm{p}-$ Yar029p and hSos $1 \mathrm{p}-$ Yar031p were unable to restore the growth of the yeast $\mathrm{CDC} 25 \mathrm{H}$ strain. These results were expected for Yar029p (see preceding section on GFP fusions) but were 


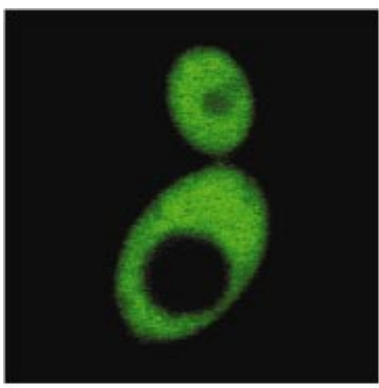

GFP alone

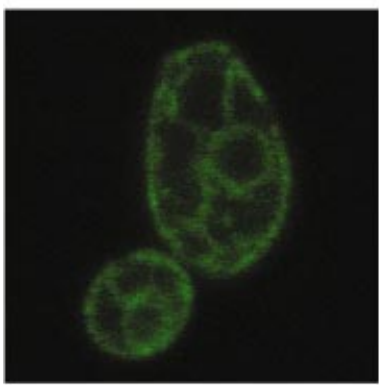

YAR033W-GFP

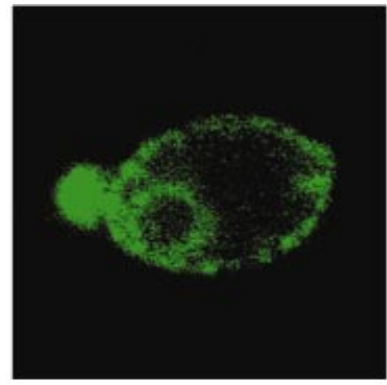

YGL051w-GFP

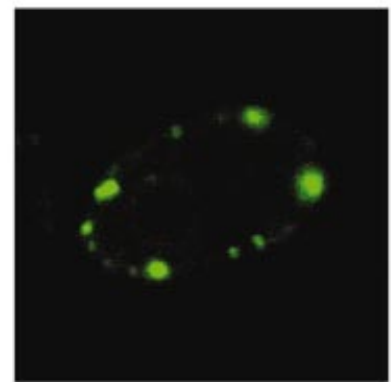

YAR031w-GFP

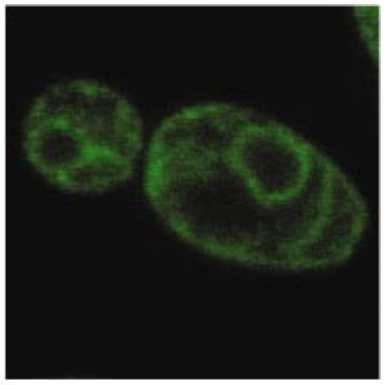

YGL053w-GFP

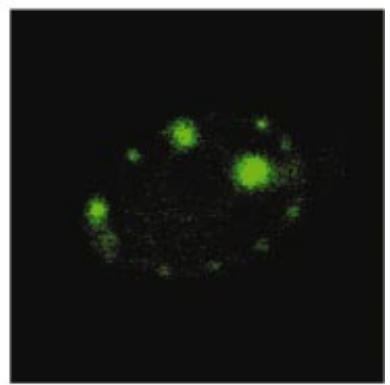

YHLO44w-GFP
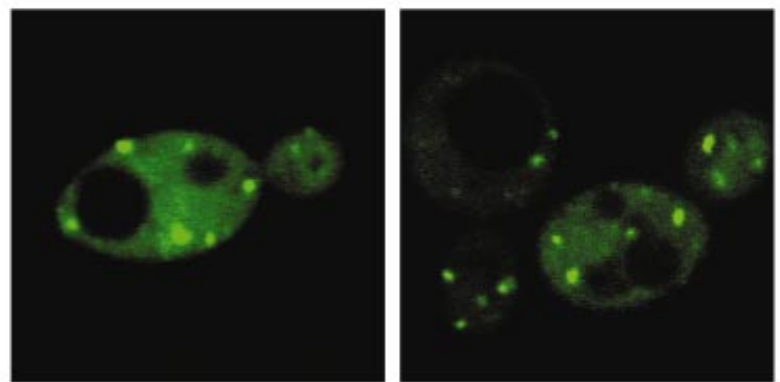

YAR029w-GFP

Fig. 6. Fluorescence micrographs of cell expressing C-terminal Dup240-GFP fusion proteins. The indicated DUP240 ORFs were cloned in-frame in front of the N-terminal of the GFP gene in PGRU1-PADH1 and expressed in the yeast strain FY1679. Cells were grown on minimal medium supplemented with the required amino acids. The localization of Dup240-GFP was determined in live cells by use of a Leica confocal microscope. The empty vector, expressing GFP alone, was used as a control.

surprising for Yar031p because the Yar031p-GFP fusion product appeared to be located at the plasma membrane.

\section{Partners that interact with the YGL051w and YGLO53w gene products as identified by two-hybrid screens}

Protein-protein interactions are essential for many biological processes. Therefore, the identification of protein partners of proteins of unknown function may help to determine the role played by these proteins in the cell. We used the two-hybrid system to screen for the protein partners of Ygl051p and Ygl053p. The entire sequences of YGL051w and YGL053w were cloned inframe with the nucleotide sequence of the Gal4p-binding domain in pGBT9 and introduced into the yeast strain PJ69-4 $\alpha$. The resulting vectors were named pGBT9YGL051w and pGBT9-YGL053w, respectively.

For YGL053w, the two-hybrid screen was performed on
$6.5 \times 10^{7}$ diploid yeast cells obtained by mating. Selection for histidine yielded 384 clones and 103 clones were obtained after selection for adenine. Seven of these clones corresponded to antisense constructs or intergenic regions, and 46 clones to the OAF1 (=YAF1) gene. As OAF1 encodes a transcription factor involved in the regulation of peroxisome proliferation and inserts of this gene were found in all the two-hybrid screenings performed in the laboratory with this library, these clones were considered to be false-positives. The twohybrid interactions with the other 50 putative positives, corresponding to 15 different inserts, were verified in another genetic context: yeast strain SFY526 (Bartel et al., 1993b) bearing the lacZ gene under the control of the GAL1 promoter. For this purpose pGBT9-empty or pGBT9-YGL053w were introduced into SFY526 simultaneously with each of the 15 plasmids encoding a putative positive partner. After $\beta$-galactosidase filter assays for all these constructs, 45 clones corresponded to 


\section{YER032w (FIRI)}
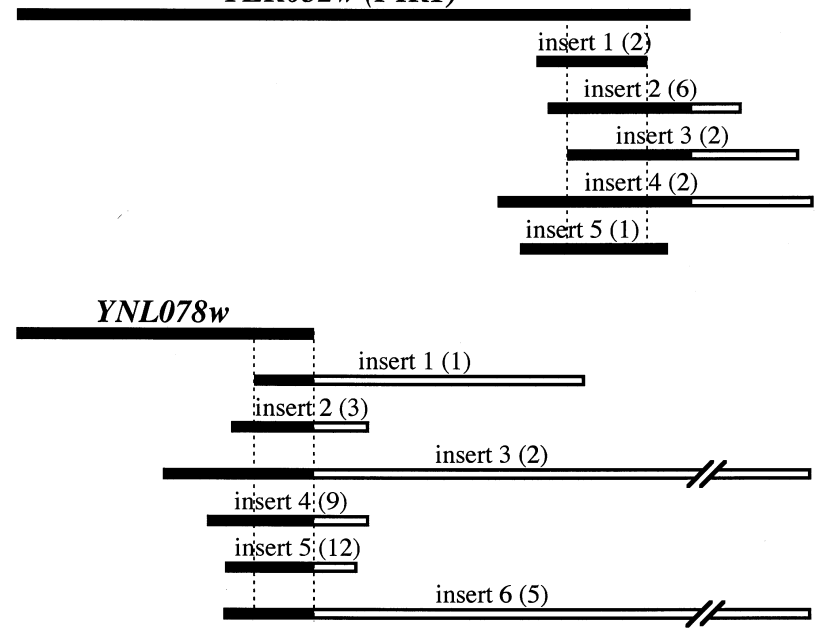

$1000 \mathrm{bp}$

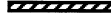

Fig. 7. Two-hybrid interactions with YGL053w. Alignments of five different inserts of YERO32w and six different inserts of YNLO78w. The region between the dotted lines is the minimal region of interaction. The sequences corresponding to the ORFs are represented in black; the sequences downstream of the stop codons are represented in white.

11 different inserts but only two different genes were retained as positives. Five of the 11 inserts corresponded to a part of the FIR1 gene (ORF of $2775 \mathrm{nt}$ ) which encodes a protein that is thought to be involved in $3^{\prime}$ mRNA processing. The five inserts contained a common sequence of $320 \mathrm{nt}$ corresponding to a region ending at $200 \mathrm{nt}$ upstream from the $3^{\prime}$ end of the FIR1 ORF (Russnak et al., 1996). The six other inserts corresponded to YNL078w, a $1221 \mathrm{nt}$ ORF of unknown function, and all of them contained the last $236 \mathrm{nt}$ of the ORF (Fig. 7).

For YGL051w, the two-hybrid screen was performed on $5.7 \times 10^{7}$ diploid yeast cells obtained by mating. Selection for histidine yielded 288 clones and final screening for adenine yielded 32 positive clones. One of these clones corresponding to an antisense construct and three clones of the OAF1 gene were eliminated. The twohybrid interactions with the other 28 putative positives, corresponding to 14 different inserts, were verified in SFY526. As for Ygl053p, the empty plasmid or the plasmid encoding Ygl051p was introduced into SFY526 simultaneously with each of the 14 plamids encoding a putative positive. After $\beta$-galactosidase filter assays, 26 clones corresponding to 12 different inserts and to 12 different ORFs were retained as positives. These positives only activated the transcription of the lac Z gene in the presence of YGLO51w. The products of these 12 ORFs were considered to be two-hybrid partners of the YGL051w product. One of these ORFs, PAN1, which coordinates regulatory interactions between proteins required for both endocytosis and the organization of the actin-cytoskeleton (Wendland \& Emr, 1998), does not encode any predicted transmembrane domain al- though its product is localized at the plasma membrane. The 11 other ORFs encode proteins with 6 to 14 known or potential transmembrane domains and are classified in the (confirmed or potential) membrane protein family (Goffeau et al., 1997). Three of these proteins are known to be localized in the plasma membrane: Gls1p, a catalytic subunit of $1,3-\beta$-D-glucan synthase involved in resistance to papulacandin B and aculeacin A (Eng et al., 1994); Rgt2p, a glucose transporter responsible for the induction of gene expression in the presence of high glucose levels, a member of the sugar permease family (Ozcan et al., 1996); and Agp3p, a member of the amino acid permease family (Nelissen et al., 1995). The eight other ORF gene products were assigned, by protein identity search, to protein families even though their specific functional roles remain unknown. Three of these, Yll028p, Ybr180p and Yor378p, are members of the multidrug resistance protein family, a subfamily of the major facilitator superfamily (MFS) and have 12, 10 and 9 putative transmembrane domains, respectively. Three others (Yil166p, Yol119p and Ykl146p) are members of MFS subfamilies and have 6, 8 and 9 putative transmembrane domains, respectively: Yil166p is similar to allantoate permease (Dal5p) and to carboxylic acid transporters and is a member of the allantoate permease family; Yol119p shows weak similarity to mammalian monocarboxylate transporters and is a member of the monocarboxylate permease family; Ykl146p shows high similarity to the hypothetical $\mathrm{C} 3 \mathrm{H} 1.09 \mathrm{c}$ protein of Schizosaccharomyces pombe. Finally Yal022p shows low similarity to a $\mathrm{Na}^{+} / \mathrm{H}^{+}$ antiporter and has nine predicted transmembrane domains, and Ybr147p has six predicted transmembrane domains. The systematic interaction of YGL051p with all of these predicted membrane proteins suggests that it is itself localized close to or at the membrane, corroborating the hSos1p fusions and GFP results.

\section{DISCUSSION}

Systematic sequencing of genomes has provided a unique opportunity to quantify the level of genetic redundancy in their nucleotide or encoded amino acid sequences. In $S$. cerevisiae most protein families contain two or three members. Large families are rare and can be used to investigate whether primary sequence redundancy is related to functional redundancy. The Dup240 protein family is composed of 10 members. As the first step of the functional analysis, we systematically knocked out all 10 members of the family. As YGL053w and YGL$051 w$ are organized in tandem repeat and YAR027w, YAR028w, YAR029w, YAR031w and YAR033w represent five direct repeats it was possible to delete all seven of these ORFs with two replacements. The single replacement of multiple ORFs has been termed 'massmurder' and is an efficient and reliable method for gene replacement (Fairhead et al., 1998). Three single conventional disruptions were required to knock out the last three ORFs. Neither single nor multiple deletions had an altered growth phenotype in the conditions tested (growth on various carbon sources 
at different temperatures, mating and sporulation assays). A similar situation has been reported for the AAD1-7 family, which encodes seven homologues to the arylalcohol dehydrogenase of the lignin-degrading fungus Phanerochaete chrysosporium (Delneri et al., 1999). However, the concurrent knock-out of 20 transporter genes was shown to be required to block glucose consumption and transport activity in $S$. cerevisiae (Wieczorke et al., 1999), and only the elimination of the entire OSBP gene family (OSH1-7) produces a lethal phenotype (Beh et al., 2001).

To learn more about the function of this multigene family we studied the subcellular localizations of the gene products and searched for interacting partners. Fluorescent staining of proteins Ygl051p, Ygl053p, Yar031p and Yar033p fused to GFP revealed that they were localized on the yeast plasma membrane and that Ygl051p, Ygl053p and Yar033p were also located in the endoplasmic reticulum. Takahashi et al. (2000) reported that YAR027p fused to GFP was localized at the nuclear envelope and plasma membrane regions. The membrane localization was further supported by the in silico analysis, which suggested that all of the proteins coded by the DUP240 ORFs (except Yar029p, which has no predicted transmembrane domain) possess two 17 aa hydrophobic predicted transmembrane domains. The activation of the RAS signalling pathway by hSos1pDup240 fusions confirmed the plasma membrane localization, showing that Ygl051p, Ygl053p and Yar033p were able to target activation in this system, either directly because they are integral membrane proteins, or indirectly by interacting with associated membrane proteins. Yar029p is much shorter than the other Dup240 proteins and Yar029p-GFP was located throughout the cytoplasm, as was GFP alone. This finding is consistent with the inability of Yar029p to target hSos1p to the RAS signalling pathway. The Yar031p protein contains 62 extra amino acids at its $\mathrm{N}$ terminus compared to Ygl053p. The C-terminal parts of these two ORFs are nevertheless highly conserved: $100 \%$ identity for the first 93 C-terminal amino acids, and only five differences among the 132 C-terminal amino acids. The identity of the $\mathrm{N}$-terminal domain of Ygl053p and the central region of Yar031p is just $41.7 \%$ (48 out of 115 amino acids). When fused to hSos1p, Yar031p was unable to activate the RAS signalling pathway despite its apparent localization as indicated by GFP fusion at the plasma membrane and the presence of two predicted transmembrane domains. This discrepancy might result from the fact that GFP-fused Yar031p always seems to form aggregates at the membrane, and may consequently be unable to target hSos1p correctly for RAS activation.

The Ygl051p and Ygl053p partners identified by screening of the two-hybrid yeast library were in different classes. The product of the ORF YGL051w fused to the binding domain of Gal4p interacted with many integral membrane proteins and many proteins of unknown function predicted to have six or more transmembrane domains. This finding further suggests that Ygl051p is located at the plasma membrane. The two-hybrid partners of Ygl053p, Fir1p and Ynl078p do not appear to be plasma membrane proteins, as they lack predicted transmembrane domains; however, this finding does not exclude a plasma membrane localization for Ygl053p. The common sequence from the different inserts encoding parts of Fir1p or Ynl078p should encode the domains from Fir1p and Ynl078p required for interaction with the Ygl053p protein. Recently, highthroughput two-hybrid screens revealed that Yar031p and Apg12p interact, and that Ygl051p and Yar033p interact (Uetz et al., 2000). We were unable to replicate this finding (data not shown). Apg12p is involved in autophagy and the targeting of proteins to the vacuole. Most free Apg12p seems to be associated with the endoplasmic reticulum (Mizushima et al., 1998). Twohybrid interactions have also been reported between Yar027p and Cks1p, an essential, physically associated, component that interacts with the protein kinase Cdc28p (Hadwiger et al., 1989), between Yar027p and Yar030p, between Ygl053p and Ylr065p, and between Yhl044p and Ykr035p (Ito et al., 2000). The Yar030p, Ylr065p and Ykr035p proteins have unknown functions but possess two and five putative transmembrane domains, respectively, so these proteins are themselves predicted to be membrane associated. The proteins coded by YGL051w, YGL053w, YAR031w and YAR033w are predicted to have structural and/or functional roles at membranes.

Our data suggest that we are dealing with a gene family specific to the genus Saccharomyces sensu stricto. This gene family belongs to the set of ascomycete-specific genes, a class of genes that tend to be more sensitive to evolutionary divergence than the average (Malpertuy et al., 2000). Even without specific information on the precise function of the proteins encoded by this gene family, we have shown that when amino acid divergence is detectable, the changes often affect a limited number of amino acids localized within a specific domain of the protein. The proteins encoded by this gene family, with the exception of Yar029p, appear to be located at membranes. We have evidence that they have specialized functions because when they were fused to GFP they did not show identical fluorescence patterns and when fused to hSos1p they did not show identical RAS activation properties. In addition, Ygl051p and Ygl053p both appear to interact with a specific set of non-redundant proteins. Thus, our data suggest that the 10 Dup240 members do not have identical functions.

\section{ACKNOWLEDGEMENTS}

We are grateful to P. Sunnerhagen and A. Ramne for providing a yeast genomic two-hybrid library, to D. Alexandraki for providing yeast transformed with this library, to M. Aigle for providing pGRU1-S65TGFP and help with the interpretation of fluorescence data, and to P. James and S. Fields for providing strains PJ69-4a and PJ69-4 $\alpha$. We are also grateful to J. Rommelaere for his kind support throughout this work. This research was supported in part by a contract within the framework of the EUROFAN project of the European Commission (BIO4-CT95-0080) to J. C. J. and by a European 
Commission Marie Curie Predoctoral Research Training fellowship BIO4-CT98-5047 to R.P.

\section{REFERENCES}

Arabidopsis Genome Initiative (2000). Analysis of the genome sequence of the flowering plant Arabidopsis thaliana. Nature 408, 796-815.

Aronheim, A., Engelberg, D., Li, N., al-Alawi, N., Schlessinger, J. \& Karin, M. (1994). Membrane targeting of the nucleotide exchange factor Sos is sufficient for activating the Ras signaling pathway. Cell 78, 949-961.

Aronheim, A., Zandi, E., Hennemann, H., Elledge, S. J. \& Karin, M. (1997). Isolation of an AP-1 repressor by a novel method for detecting protein-protein interactions. Mol Cell Biol 17, 30943102.

Bartel, P. L., Chien, C. T., Sternglanz, R. \& Fields, S. (1993a). Using the two-hybrid system to detect protein-protein interactions. In Cellular Interactions in Development: a Practical Approach, pp. 153-179. Edited by D. A. Hartley. Oxford: Oxford University Press.

Bartel, P. L., Chien, C. T., Sternglanz, R. \& Fields, S. (1993b). Elimination of false positives that arise in using the two-hybrid system. Biotechniques 14, 920-924.

Barton, A. B., Bussey, H., Storms, R. K. \& Kaback, D. B. (1997). Molecular cloning of chromosome I DNA from Saccharomyces cerevisiae: characterization of the $54 \mathrm{~kb}$ right terminal CDC15FLO1-PHO11 region. Yeast 13, 1251-1263.

Beh, C. T., Cool, L., Phillips, J. \& Rine, J. (2001). Overlapping functions of the yeast oxysterol-binding protein homologues. Genetics 157, 1117-1140.

Bendixen, C., Gangloff, S. \& Rothstein, R. (1994). A yeast matingselection scheme for detection of protein-protein interactions. Nucleic Acids Res 22, 1778-1779.

Blandin, G., Durrens, P., Tekaia, F. \& 19 other authors (2000). Genomic exploration of the hemiascomycetous yeasts. 4. The genome of Saccharomyces cerevisiae revisited. FEBS Lett 487, 31-36.

Bon, E., Neuveglise, C., Casaregola, S., Artiguenave, F., Wincker, P., Aigle, M. \& Durrens, P. (2000). Genomic exploration of the hemiascomycetous yeasts. 5. Saccharomyces bayanus var. uvarum. FEBS Lett 487, 37-41.

Brachmann, C. B., Davies, A., Cost, G. J., Caputo, E., Li, J., Hieter, P. \& Boeke, J. D. (1998). Designer deletion strains derived from Saccharomyces cerevisiae S288C: a useful set of strains and plasmids for PCR-mediated gene disruption and other applications. Yeast 14, 115-132.

Chardin, P., Camonis, J. H., Gale, N. W., van Aelst, L., Schlessinger, J., Wigler, M. H. \& Bar-Sagi, D. (1993). Human Sos1: a guanine nucleotide exchange factor for Ras that binds to Grb2. Science 260, 1338-1343.

Delneri, D., Gardner, D. C., Bruschi, C. V. \& Oliver, S. G. (1999). Disruption of seven hypothetical aryl alcohol dehydrogenase genes from Saccharomyces cerevisiae and construction of a multiple knock-out strain. Yeast 15, 1681-1689.

Dujon, B. (1998). European Functional Analysis Network (EUROFAN) and the functional analysis of the Saccharomyces cerevisiae genome. Electrophoresis 19, 617-624.

Eng, W. K., Faucette, L., McLaughlin, M. M., Cafferkey, R., Koltin, Y., Morris, R. A., Young, P. R., Johnson, R. K. \& Livi, G. P. (1994). The yeast FKS1 gene encodes a novel membrane protein, mutations in which confer FK506 and cyclosporin A hypersensitivity and calcineurin-dependent growth. Gene 151, 61-71.
Fairhead, C., Thierry, A., Denis, F., Eck, M. \& Dujon, B. (1998). 'Mass-murder' of ORFs from three regions of chromosome XI from Saccharomyces cerevisiae. Gene 223, 33-46.

Feuermann, M., de Montigny, J., Potier, S. \& Souciet, J. L. (1997). The characterization of two new clusters of duplicated genes suggests a 'Lego' organization of the yeast Saccharomyces cerevisiae chromosomes. Yeast 13, 861-869.

Fields, S. \& Song, O. (1989). A novel genetic system to detect protein-protein interactions. Nature 340, 245-246.

Fromont-Racine, M., Rain, J. C. \& Legrain, P. (1997). Toward a functional analysis of the yeast genome through exhaustive twohybrid screens. Nat Genet 16, 277-282.

Georgakopoulos, T., Koutroubas, G., Vakonakis, I., Tzermia, M., Prokova, V., Voutsina, A. \& Alexandraki, D. (2001). Functional analysis of the Saccharomyces cerevisiae YFR021w/YGR223c/ YPL100w ORF family suggests relations to mitochondrial/ peroxisomal functions and amino acid signalling pathways. Yeast $18,1155-1171$.

Gietz, R. D., Schiestl, R. H., Willems, A. R. \& Woods, R. A. (1995). Studies on the transformation of intact yeast cells by the LiAc/SSDNA/PEG procedure. Yeast 11, 355-360.

Goffeau, A., Park, J., Paulsen, I. T., Jonniaux, J. L., Dinh, T., Mordant, P. \& Saier, M. H. (1997). Multidrug-resistant transport proteins in yeast: complete inventory and phylogenetic characterization of yeast open reading frames with the major facilitator superfamily. Yeast 13, 43-54.

Hadwiger, J. A., Wittenberg, C., Mendenhall, M. D. \& Reed, S. I. (1989). The Saccharomyces cerevisiae CKS1 gene, a homolog of the Schizosaccharomyces pombe suc1 ${ }^{+}$gene, encodes a subunit of the Cdc28 protein kinase complex. Mol Cell Biol 9, 2034-2041.

Hoffman, C. S. \& Winston, F. (1987). A ten-minute DNA preparation from yeast efficiently releases autonomous plasmids for transformation of Escherichia coli. Gene 57, 267-272.

Ito, T., Tashiro, K., Muta, S., Ozawa, R., Chiba, T., Nishizawa, M., Yamamoto, K., Kuhara, S. \& Sakaki, Y. (2000). Toward a proteinprotein interaction map of the budding yeast: a comprehensive system to examine two-hybrid interactions in all possible combinations between the yeast proteins. Proc Natl Acad Sci US A 97, 1143-1147.

James, P., Halladay, J. \& Craig, E. A. (1996). Genomic libraries and a host strain designed for highly efficient two-hybrid selection in yeast. Genetics 144, 1425-1436.

Jelinsky, S. A. \& Samson, L. D. (1999). Global response of Saccharomyces cerevisiae to an alkylating agent. Proc Natl Acad Sci U S A 96, 1486-1491.

Johnston, S. A. \& Carlson, M. (1992). Regulation of carbon and phosphate utilization. In The Molecular and Cellular Biology of the Yeast Saccharomyces, Gene Expression, pp. 193-281. Edited by E. W. Jones, J. R. Pringle \& J. R. Broach. Cold Spring Harbor, NY: Cold Spring Harbor Laboratory.

Karin, M., Najarian, R., Haslinger, A., Valenzuela, P., Welch, J. \& Fogel, S. (1984). Primary structure and transcription of an amplified genetic locus: the CUP1 locus of yeast. Proc Natl Acad Sci U S A 81, 337-341.

Klein, P., Kanehisa, M. \& DeLisi, C. (1985). The detection and classification of membrane-spanning proteins. Biochim Biophys Acta 815, 468-476.

Malpertuy, A., Tekaia, F., Casaregola, S. \& 21 other authors (2000). Genomic exploration of the hemiascomycetous yeasts. 19. Ascomycetes-specific genes. FEBS Lett 487, 113-121.

Mizushima, N., Noda, T., Yoshimori, T., Tanaka, Y., Ishii, T., George, M. D., Klionsky, D. J., Ohsumi, M. \& Ohsumi, Y. (1998). A 
protein conjugation system essential for autophagy. Nature 395, 395-398.

Muhlrad, D., Hunter, R. \& Parker, R. (1992). A rapid method for localized mutagenesis of yeast genes. Yeast $\mathbf{8}, 79-82$.

Nelissen, B., Mordant, P., Jonniaux, J. L., De Wachter, R. \& Goffeau, A. (1995). Phylogenetic classification of the major superfamily of membrane transport facilitators, as deduced from yeast genome sequencing. FEBS Lett 377, 232-236.

Oliver, S. G., Winson, M. K., Kell, D. B. \& Baganz, F. (1998). Systematic functional analysis of the yeast genome. Trends Biotechnol 16, 373-378.

Ozcan, S., Dover, J., Rosenwald, A. G., Wolfl, S. \& Johnston, M. (1996). Two glucose transporters in Saccharomyces cerevisiae are glucose sensors that generate a signal for induction of gene expression. Proc Natl Acad Sci U S A 93, 12428-12432.

Petitjean, A., Hilger, F. \& Tatchell, K. (1990). Comparison of thermosensitive alleles of the CDC25 gene involved in the cAMP metabolism of Saccharomyces cerevisiae. Genetics 124, 797-806.

Rachidi, N., Martinez, M. J., Barre, P. \& Blondin, B. (2000). Saccharomyces cerevisiae PAU genes are induced by anaerobiosis. Mol Microbiol 35, 1421-1430.

Russnak, R., Pereira, S. \& Platt, T. (1996). RNA binding analysis of yeast REF2 and its two-hybrid interaction with a new gene product, FIR1. Gene Expr 6, 241-258.

Saiki, R. K., Scharf, S., Faloona, F., Mullis, K. B., Horn, G. T., Erlich, H. A. \& Arnheim, N. (1985). Enzymatic amplification of betaglobin genomic sequences and restriction site analysis for diagnosis of sickle cell anemia. Science 230, 1350-1354.

Sambrook, J., Fritsch, E. F. \& Maniatis, T. (1989). Molecular Cloning: a Laboratory Manual, 2nd edn. Cold Spring Harbor, NY: Cold Spring Harbor Laboratory.

Sander, C. \& Schneider, R. (1991). Database of homology-derived protein structures and the structural meaning of sequence alignment. Proteins 9, 56-68.
Schneller, J. M., Schneider, C. \& Stahl, A. J. (1978). Distinct nuclear genes for yeast mitochondrial and cytoplasmic methionyltRNA synthetases. Biochem Biophys Res Commun 85, 1392-1399.

Sherman, F., Fink, G. R. \& Hicks, J. B. (1986). Methods in Yeast Genetics. Cold Spring Harbor, NY: Cold Spring Harbor Laboratory.

Souciet, J., Aigle, M., Artiguenave, F. \& 21 other authors (2000). Genomic exploration of the hemiascomycetous yeasts. 1. A set of yeast species for molecular evolution studies. FEBS Lett 487, 3-12.

Takahashi, Y., Mizoi, J., Toh, E. A. \& Kikuchi, Y. (2000). Yeast Ulp1, an Smt3-specific protease, associates with nucleoporins. $J$ Biochem 128, 723-725.

Uetz, P., Giot, L., Cagney, G. \& 17 other authors (2000). A comprehensive analysis of protein-protein interactions in Saccharomyces cerevisiae. Nature 403, 623-627.

Wach, A., Brachat, A., Pohlmann, R. \& Philippsen, P. (1994). New heterologous modules for classical or PCR-based gene disruptions in Saccharomyces cerevisiae. Yeast 10, 1793-1808.

Wagner, R., Straub, M. L., Souciet, J. L., Potier, S. \& de Montigny, J. (2001). New plasmid system to select for Saccharomyces cerevisiae purine-cytosine permease affinity mutants. J Bacteriol 183, 4386-4388.

Wendland, B. \& Emr, S. D. (1998). Pan1p, yeast Eps15, functions as a multivalent adaptor that coordinates protein-protein interactions essential for endocytosis. J Cell Biol 141, 71-84.

Wieczorke, R., Krampe, S., Weierstall, T., Freidel, K., Hollenberg, C. P. \& Boles, E. (1999). Concurrent knock-out of at least 20 transporter genes is required to block uptake of hexoses in Saccharomyces cerevisiae. FEBS Lett 464, 123-128.

Received 5 December 2001; revised 4 March 2002; accepted 20 March 2002. 